\title{
POWER QUALITY IMPROVEMENT USING IMPEDANCE NETWORK BASED INVERTER
}

\author{
Amitava Das ${ }^{1}$, Sudipta Bhui ${ }^{2}$, Partha Sarathi Mondal ${ }^{3}$ \\ ${ }^{1}$ Electrical \& Electronics Engineering Department, NSHM Knowledge Campus West Bengal, India \\ ${ }^{2,3}$ Electrical Engineering Department, BCREC, West Bengal, India, \\ amitava.das@nshm.com, sudipta.bhui@gmail.com,partha.mondal28@gmail.com
}

\begin{abstract}
Inverters are suited for applications where DC supply is converted to AC signal with desired waveform \& adequate quality of power. Recently proposed Trans $Z$-source inverters and $T$-source inverters characterize improved power quality with the help of coupled inductors with turn's ratio higher than one. This paper presents the concept of LC network based inverter. The built in DC current blocking capacitors connected in series with transformer windings and therefore prevent the transformer core from saturation. The novel LC network based inverter topology proposed in this paper characterize available continuous input current which is the advantage compared to TZSI and TSI. Simulations have been carried out in PSIM platform and results are presented to validate the proposed topology of the inverter system.
\end{abstract}

Index Terms: Power quality, LC network, Impedance source inverter, Boost control, Shoot through state.

\section{INTRODUCTION}

The increase of non-linear load due to proliferation of electronic equipment causes power quality in the power system to deteriorate. The Z-source inverters are one stage energy processing buck-boost inverters that are of great potential for power quality improvement in renewable energy systems. They contain unique passive input impedance networks [1] and utilize the shoot-through of the inverter bridge to boost DC input voltage. The ZSI was expected to be suitable interface for renewable generation units as its LC Z-network allows the input DC voltage to be varied as desired and its voltage boost gain can be theoretically infinite. Unfortunately, the ZSI boost ratio $B$ and the modulation index $M$ are interdependent which means that the increase in boost factor $B$ results in lower modulation index M. Therefore in some low DC voltage applications which require a high voltage gain a disadvantageously small modulation index has to be used. Basic ZSI topology [1] suffers from discontinuous input current characterizing large di/dt and requires additional input filter which increases the element count and costs.

The recent achievements in $\mathrm{SiC}$ material and device technology, particularly the increase in available operating frequency of power devices give the possibility to decrease the volume and increase the power quality of power electronic converters. This paper proposed the impedance network and transformer based inverter for power quality improvement in various applications

\section{PROPOSED IMPEDANCE SOURCE INVERTER}

The proposed impedance source inverter which is called LC network based inverter can be derived from basic $\mathrm{Z}$ - source inverter using the modification of impedance network. The method of obtaining different LC networks from the basic Zsource network as shown in Fig 1
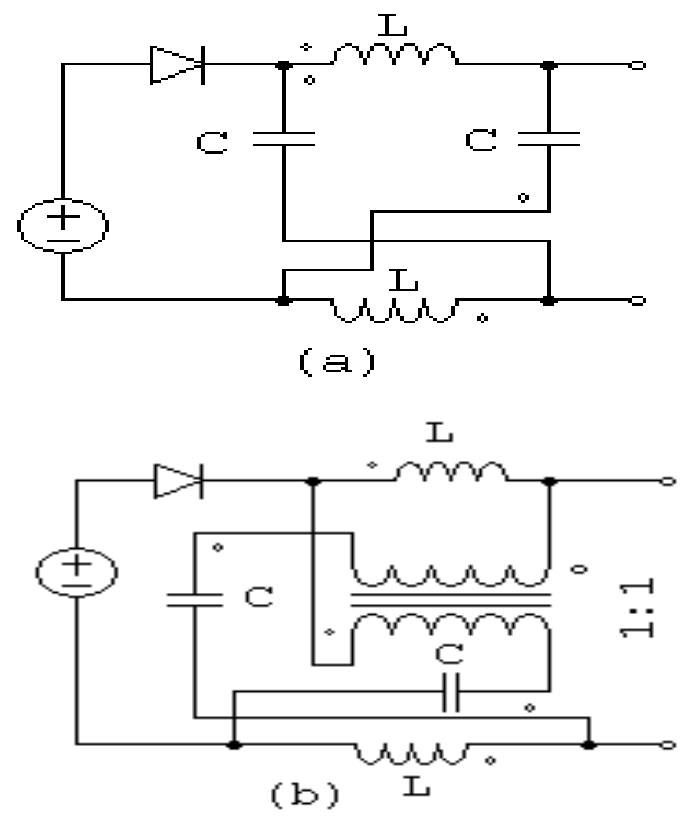

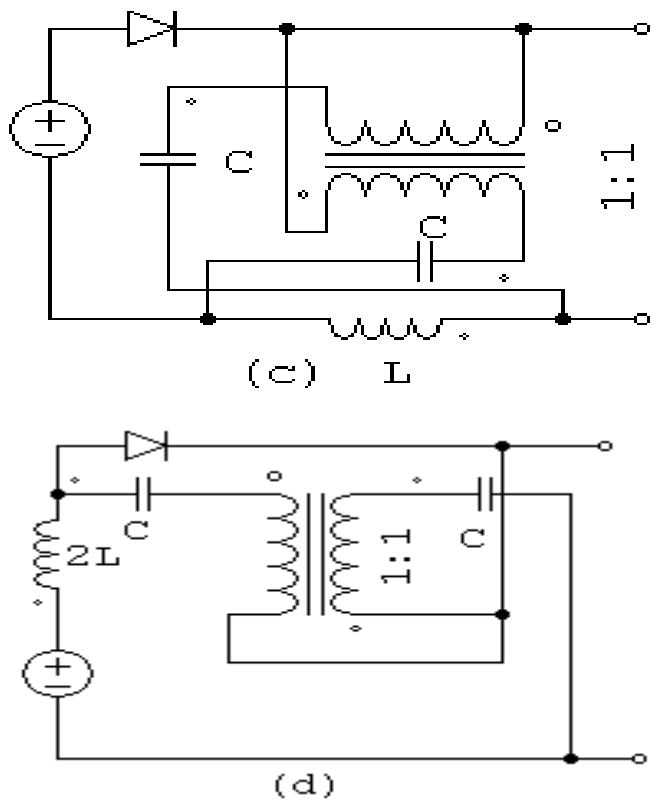

Fig-1: Modification of basic impedance source (a) conventional $\mathrm{Z}$-source (b) transformer based equivalent circuit

(c) discontinuous input current LC network (d) continuous input current LC network

The circuit schematic of the proposed new type LC network inverter with inverted winding orientation of the transformer and two built-in DC-current blocking capacitors $\mathrm{C} 1$ and $\mathrm{C} 2$ is shown in Fig. 2. The occurrence of the two built-in DC current blocking capacitors is the main benefit of this proposed inverter over the ZSI. The unique property of this inverter is that no energy is stored in the transformer windings. The two DCcurrent blocking capacitors connected in series with the transformer also prevent the transformer core from saturation.

\section{PRINCIPLE OF OPERATION}

The proposed inverter is described and shown in Fig. 2. The characteristic waveforms of the proposed inverter from Fig. 3

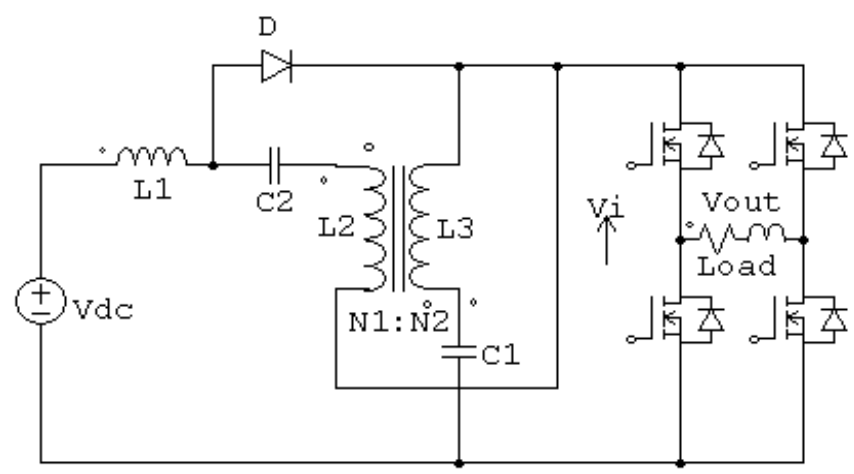

Fig-2: Proposed Impedance network based inverter during the three operating modes: shoot-through mode (duration T0), non shoot-through mode with ID>0 (duration T1) and non shoot through mode with ID=0 (duration T2).
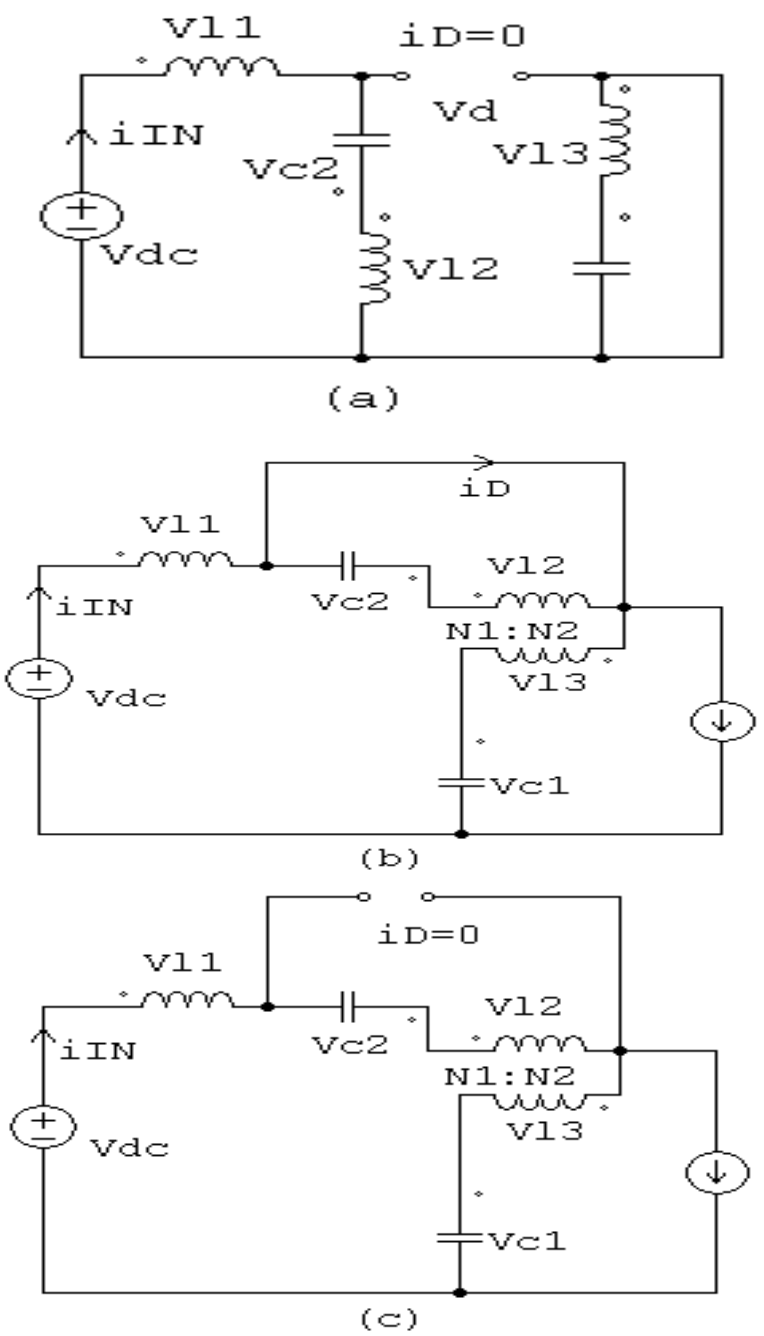

Fig-3: Equivalent circuit in three operation modes (a) shoot through mode (b) non shoot through mode ID $>0$ (c) ID $=0$.

The relationship of the capacitor voltages $\mathrm{VC} 1$ and $\mathrm{VC} 2$ are constant. DC source input voltage VDC in the steady state is related by the following equation:

$$
V_{C 2}=V_{C 1}-V_{D C}
$$

For input inductor L1 and input diode D voltages VL1 and VD and transformer voltages VL2 and VL3 can be written as:

$$
V_{L 2}=\left(\frac{N_{1}}{N_{2}}\right) V_{L 2}
$$


For inductors voltages VL1, VL2, VL3 we have:

$$
V_{L 1}=-\left(V_{L 2}-V_{L 3}\right)
$$

This describes the use of common core both for the transformer and input inductor. Because the inverted orientation of the transformer windings the DC link voltage $\mathrm{Vi}$ is equal:

$$
V_{i}=V_{C 1}-V_{L 3}
$$

Fig. 2(a) to Fig. 2(c) describes the equivalent circuits of proposed inverter during different operation modes. For the shoot-through mode during the interval T0 (Fig. 2a) it appears:

$$
\begin{gathered}
V_{L 3}=V_{C 1}, V_{L 2}=\left(\frac{N_{1}}{N_{2}}\right) V_{L 1} \\
V_{L 1}=-\left(1+\frac{N_{1}}{N_{2}}\right) V_{C 1}
\end{gathered}
$$

For the non shoot-through state with conducting input diode (first active state) during the interval $\mathrm{T} 1$ from the equivalent circuit, Fig. 2(b) for the input inductor L1 and transformer windings L2, L3 it can be written as:

$$
\begin{gathered}
V_{L 2}=-V_{C 2}, V_{L 3}=-\left(\frac{N_{2}}{N_{1}}\right) V_{C 2} \\
V_{L 1}=\left(1+\frac{N_{2}}{N_{1}}\right) V_{C 2}
\end{gathered}
$$

During the second active state for an interval $\mathrm{T} 2$ from the equivalent circuit from Fig. 2(c), it can be written as:

$$
V_{L 1}=0, \quad V_{L 2}=0, \quad V_{L 3}=0 \quad \& V_{i}=V_{C 1}
$$

The output voltage of the LC network based inverter can be controlled by the control of the capacitor $\mathrm{C} 1$ voltage. In the steady state the VC1 can be calculated as:

$$
V_{C 1}=\frac{1-D}{1-\left(1+\frac{N_{1}}{N_{2}}\right) D} V_{D C}
$$

\begin{tabular}{|c|c|c|c|c|c|}
\hline \multirow[b]{2}{*}{$\begin{array}{c}\text { Various } \\
\text { improvements }\end{array}$} & \multicolumn{5}{|c|}{ Inverter } \\
\hline & $\begin{array}{c}\text { Propose } \\
\quad d \\
\text { inverter }\end{array}$ & $\begin{array}{c}\text { TSI, } \\
\text { TZS } \\
\text { I, } \\
\text { TqZ } \\
\text { SI }\end{array}$ & $\begin{array}{c}\text { EBZ } \\
\text { SI }\end{array}$ & $\begin{array}{c}\text { CqZSI } \\
\quad, \\
\text { SIZSI }\end{array}$ & $\begin{array}{l}\text { EZSI, } \\
\text { qZSI }\end{array}$ \\
\hline $\begin{array}{l}\text { Continuous } \\
\text { Input Current }\end{array}$ & Yes & No & Yes & No & Yes \\
\hline $\begin{array}{c}\text { EMI } \\
\text { improvement }\end{array}$ & Yes & No & Yes & No & Yes \\
\hline $\begin{array}{c}\text { No of } \\
\text { Elements }\end{array}$ & $\begin{array}{l}\text { Significa } \\
\text { ntly } \\
\text { reduced }\end{array}$ & $\begin{array}{l}\text { Red } \\
\text { uce }\end{array}$ & $\begin{array}{c}\text { Incre } \\
\text { ase }\end{array}$ & $\begin{array}{c}\text { Increas } \\
\mathrm{e}\end{array}$ & $\begin{array}{l}\text { Unch } \\
\text { anged }\end{array}$ \\
\hline $\begin{array}{l}\mathrm{MB}-\mathrm{M} \\
\text { relationship }\end{array}$ & Yes & Yes & Yes & Yes & No \\
\hline
\end{tabular}

Comparisons of proposed impedance network based inverter with the several improvements of the basic ZSI topology have been recently obtained [2] - [10] as shown in Table - 1 .
Table -1: Comparison of Proposed Inverter with Different Types of ZSI

\section{SIMULATION AND RESULT}

The transformer with the turns ratio set to 20:1 was used. The input inductor L1 is $3 \mathrm{mH}$. Two capacitors: the built in DCcurrent-blocking capacitor $\mathrm{C} 1=400 \mathrm{uF}$ and the capacitor $\mathrm{C} 2$ $=140 \mathrm{uF}$ paralleling the DC link circuit during active mode operation were used.

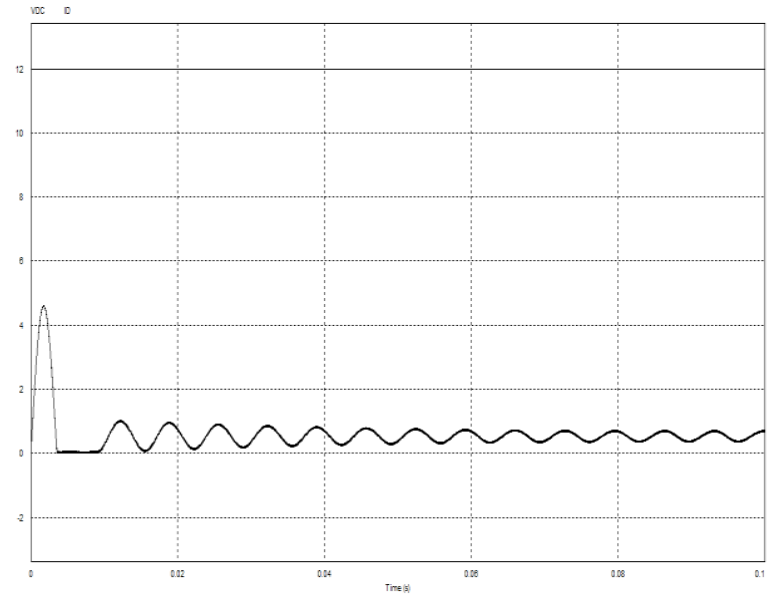

Fig-4: DC input voltage VDC and diode current ID 


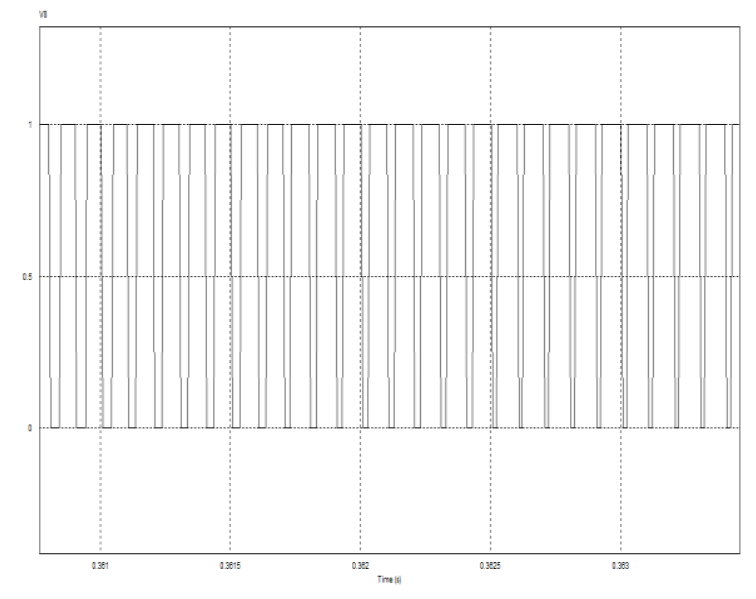

Fig-5: PWM signal waveform

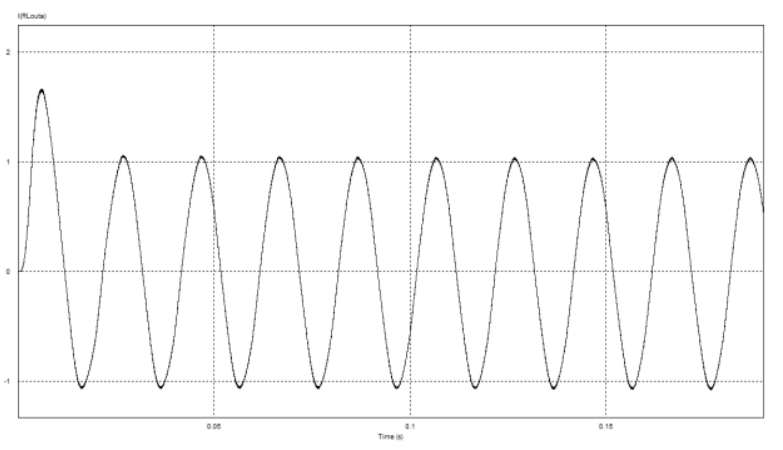

Fig-6: Output current waveform of RL load

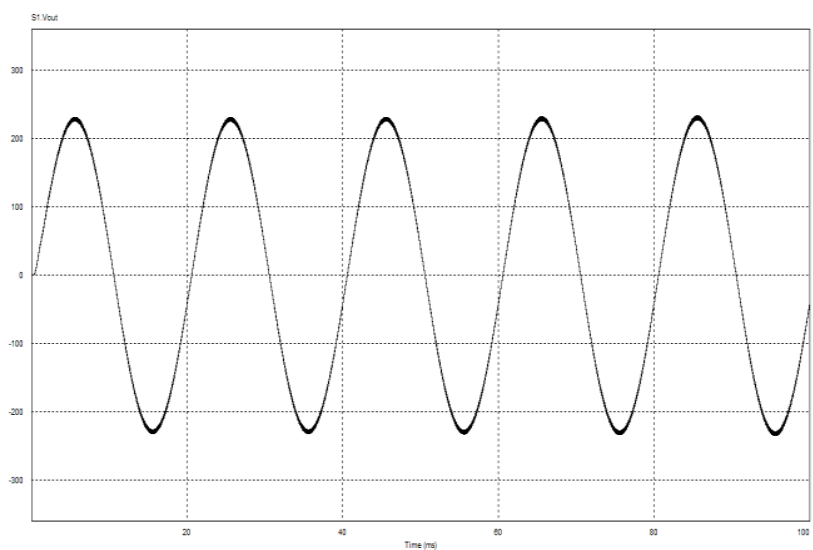

Fig-7: Output voltage waveform of RL load.

The transformer leakage inductance seen from the primary was set to minimize the negative impact of voltage spikes. The switching frequency of the system was $10 \mathrm{kHz}$. Light load operation of inverter was investigated to examine the theoretical analysis given in previous chapters. Figure 4 to
Figure 7 shows the simulation results from the LC network based inverter system fed from $12 \mathrm{~V}$ battery or PV cell and loaded with RL load. Simulations were carried out using the PSIM Simulation software.

\section{CONCLUSIONS}

The proposed topology of LC networked based inverter improved performance over the recently proposed Trans-Zsource and $\mathrm{T}$-source inverters. This inverter characterizes available continuous input current even during light-load operation. The negative impact of parasitic parameters of coupled inductors on the DC link voltage is significantly reduced. The unique topology of LC passive input circuit helps to prevent the transformer core from saturation. Due to application of two built-in DC current blocking capacitors in the circuit, no energy is stored in the two windings of the integrated transformer. Only one inductive element is used to store the energy during the boost operation. The average currents of two transformer windings over the period of the output voltage are equal zero. The inverters proposed in the paper are interesting alternative to other Z-source inverter modifications. Additionally they characterize reduced element count when compared to recently developed CqZSIs and EBZSI operated with the same voltage gain and the same shoot through ratio. Proposed topology can be further optimized using higher switching frequency of power devices (SiC transistors and $\mathrm{SiC}$ diodes). Therefore power quality improvement at output is expected to obtain with proposed inverter.

\section{REFERENCES}

[1] Peng F.Z., Z-Source Inverter, IEEE Trans. Ind. Applications Vol. 39, no 2, 2003,pp. 504-510

[2] Loh P.C., Gao F., Blaabjerg F., Goh A.L., Buck-Boost Impedance Networks, Proc. European Conference on Power Electronics EPE 2007, CD-ROM, pp. 1-10.

[3] Anderson J., Peng F.Z., Four Quasi-Z-Source Inverters, IEEE Conference PESC'08, 2008, pp. 2743 - 2749.

[4] R. Strzelecki, M. Adamowicz, N. Strzelecka and W. Bury, New type T-Source inverter, IEEE Conf.Compatibility and Power Electronics, CPE '09, 2009, pp. $191-195$

[5] W. Qian, F. Z. Peng; H. Cha, Trans-Z-source inverters, Proc. IEEE Int. Power Electronics Conference IPEC, 2010, pp. $1874-1881$

[6] C.J. Gajanayake, F. L. Luo; H. B. Gooi, P. L. So, L. K. Siow, Extended-Boost Z- Source Inverters, IEEE Transactions on Power Electronics, vol. 25 , n. 10, 2010, pp. $2642-2652$

[7] Miao Zhu, Kun Yu, Fang Lin Luo: Switched Inductor ZSource Inverter, IEEE Trans. Power Electron., Vol. 25 , no. 8, 2010, pp. $2150-2158$

[8] Rabkowski J., Barlik R., Nowak M., Pulse Width Modulation Methods for Bidirectional/High Performance 
Z-source Inverter, Proc. of IEEE Power Electronics Specialists Conf. PESC'08 (2008), 2750-2756.

[9] M. Shen, J. Wang, A. Joseph, F. Z. Peng, L.M. Tolbert, D.J. Adams, Constant boost control of the Z-source inverter to minimize current ripple and voltage stress, IEEE Transactions on Industry Applications, vVol. 42, no. 3, 2006, pp. $770-778$.

[10] P.A. Janse van Rensburg, J.D. van Wyk, J.A. Ferreira: Design, prototyping and assessment of a $3 \mathrm{~kW}$ integrated LCT component for deployment in various resonant converters, IET Power Electronics, 2009, Vol. 2, No. 5, pp. 535-544.

[11] M.B.Gerber, W.Hofsajer, W.A.Cronje: Construction and modelling of a planar multi-layer electromagnetically integrated LCCT component, Proc. IEEE Industry Applications Conference, 2000, Vol. 5, pp. $3044-3050$.

[12] Nejadpak A., Barzegaran M.R., Sarikhani A., Mohammed, O.A., Design of Planar Inductor Based Zsource Inverter for Residential Alternate Energy Sources, Proc. Twenty-Sixth Annual IEEE Applied Power Electronics Conference and Exposition (APEC).

\section{BIOGRAPHIES:}

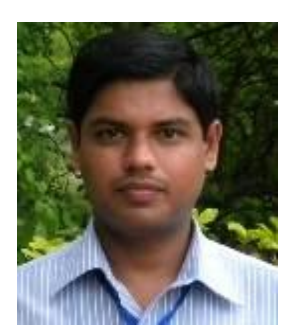

Amitava Das M'07 received his M.Tech degree in Electrical Engineering from NIT Durgapur, India and pursuing $\mathrm{PhD}$ in Electrical Engineering from NIT Silchar, India. He has served Electrical \& Electronics Engineering Dept., NSHM knowledge Campus, Durgapur, India as Assistant Professor from Jan 2013 to present. His research interest in DC - DC converter, DC- AC converter, Power Quality improvement, power electronics application to renewable energy etc. He is a Member of the IEEE (USA).

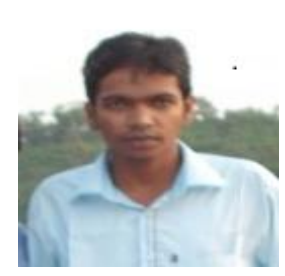

Sudipta Bhui received his B.Tech in electrical engineering from Bankura Unnayani Institute of Engineering, West Bengal, india. Now pursuing M.tech in power system engineering from BCREC, Durgapur, india.

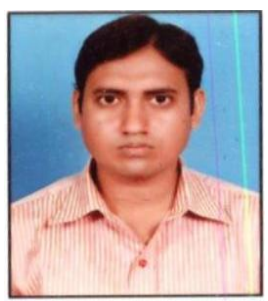

Partha Sarathi Mondal received his B.Tech in electrical engineering from Asansol Engineering College, West Bengal, india. Now pursuing M.tech in power system engineering from BCREC, Durgapur, india. 